\title{
Thermoelectric Modeling and Online SOC Estimation of Li-Ion Battery for Plug-In Hybrid Electric Vehicles
}

\author{
Aishwarya Panday, Hari Om Bansal, and Pramod Srinivasan \\ Electrical and Electronics Engineering Department, B.I.T.S. Pilani, Jhunjhunu, Rajasthan 333031, India \\ Correspondence should be addressed to Aishwarya Panday; aishwarya.panday@pilani.bits-pilani.ac.in
}

Received 21 September 2015; Revised 26 November 2015; Accepted 14 December 2015

Academic Editor: Joseph Virgone

Copyright ( 2016 Aishwarya Panday et al. This is an open access article distributed under the Creative Commons Attribution License, which permits unrestricted use, distribution, and reproduction in any medium, provided the original work is properly cited.

The increasing oil price, energy demand, and environmental concern are leading to a global switch towards Plug-In Hybrid Electric Vehicles (PHEVs). In a PHEV, Li-ion battery is considered as the primary propelling source. Therefore, an accurate battery model is required to predict the $I-V$ characteristic and dynamic behavior of a battery. This paper presents a highly effective thermoelectric model of Li-ion battery developed in Simulink. An algorithm is proposed for estimation of state of charge (SOC) and open circuit voltage (OCV) adaptively to notify the exact SOC level for better utilization of battery power and optimal vehicle performance. Thermal behavior of Li-ion battery is investigated for wide temperature range and its effect on resistance, capacity, and OCV is recorded. The minimum SOC level to which battery can get depleted is calculated using gradient method. The proposed simulation results are analyzed with those of earlier models and found to be better.

\section{Introduction}

Internal Combustion Engine (ICE) based automobiles have been causing toxic emissions, global warming, and environmental and ecological danger. Petroleum as a finite fuel and increasing prices of crude oil were motivation to find alternative approaches to propel vehicles. The world is now moving towards hybrid vehicles, which contain an alternative power source along with ICE to reduce the liquid fuel consumption without affecting vehicle performance.

Hybrid Electric Vehicles (HEVs) and PHEVs are now available in the market with reduced petroleum consumption. In PHEV, the battery is used as primary power source and ICE as secondary power source. It provides a longer driving range and easy refueling (recharging) with reduced liquid fuel consumption and toxic emissions. Thus, PHEV is a means to reduce the energy demand and replacing the liquid fuel consumption by storing electrical energy in large on-board rechargeable batteries with high fuel economy and better energy efficiency [1].

Depending upon the application and specification different types of batteries are available in market like leadacid, Nickel, and Li-ion based batteries. Among these, Li-ion batteries are preferred in portable electronics today because they provide higher specific energy, higher specific density, extra durability, and lower self-discharge rate with better safety issues $[2,3]$.

Since batteries play a vital role in PHEVs, it is essential to study their behavior. A holistic understanding of the same would result in better performance of the vehicle. The battery can be modeled using electrochemical, mathematical, analytical and stochastic, impedance based, and electrical circuit based models. The electrical circuit based model depicts the battery behavior easily [4]. Electric models are of varying degrees of complexity to capture battery performance with respect to a set of parameters which are explained in detail in the next section. In this paper, a second-order electrical battery model considering diffusion and double layer effects and self-discharge current is proposed. It reflects the effect of temperature on various parameters. And a modified SOC estimation is considered here which incorporates both open circuit voltage method and ampere hour counting. To inquire about instantaneous SOC and OCV during battery usage, an adaptive estimation algorithm is developed. To use the battery, effectively without deteriorating battery health, the threshold SOC value of the battery is also computed. 
This paper is organized with different sections; unfolding existing battery models in literature is in Section 2. Section 3 contains the proposed SOC estimation method with the detailed description of weighting factor and correction factor. Section 4 describes the development of the proposed 2RC thermoelectric model. Section 5 discusses the simulation results. Section 6 determines the threshold SOC and Section 7 finally concludes the paper.

\section{Overview of Existing Models}

Sean proposes a PSPICE macromodel showing the voltage dependency on SOC, discharge current, resistance, and capacity variation with respect to temperature [5]. This is further used by [6] to propose a discrete-time model which is capable of battery lifetime estimation. In 1994, The National Renewable Energy Laboratory (NREL) modeled Liion battery with a voltage source and internal resistance as a function of SOC, temperature, and current flow direction in ADVISOR. Saft America developed the high-power Liion cells and implemented 2-capacitance battery model in PSPICE. It shows a slightly better performance in comparison to NREL's model [7]. Chen et al. proposed a model to be used with an equilibrium potential and two internal resistances $R_{1}$ and $R_{2}$ where $R_{1}$ is a function of discharge current, temperature, and life cycle and $R_{2}$ is a function of state of discharge and temperature but did not count for transient response of the battery [8].

Gao et al. demonstrated a dynamic model of Li-ion battery which depicts a capacity variation on the basis of C-rate and temperature change, equilibrium potential, and transient response of the battery [9]. It consists of equilibrium potential, internal resistance (with two components), and a capacitor (transient response of charge double layer) but may result in a better performance by involving self-discharge current and diffusion effect between electrodes. Tremblay et al. presented a battery model, for dynamic simulation software, and added the same in the SimPowerSystems library MATLAB/Simulink. It consists of an internal resistance and a voltage source which is a nonlinear function of battery SOC. It does not account for Peukert, self-discharge, memory effect, and temperature variation [10].

Lee et al. used Li-ion battery model with internal resistance, one RC combination, and a voltage source (OCV as a function of SOC). They estimated SOC using ampere-hour counting and capacity estimation, neglecting coulomb based counting which is also required for accurate SOC estimation [11]. Using lumped model, the SOC estimation algorithm is developed at varying temperatures $[12,13]$. It consists of one resistance with two components (series and charge transfer), one RC ladder (diffusion resistance and diffusion capacitance), and voltage source (OCV) but does not account for self-discharge current and transient behavior of a battery. Bhide and Shim developed a circuit based Li-ion battery model using AMESim and also represented the temperature rise in core and the crust. But the model considers only particular discharge rate and different temperature and discharge rate factor functions for different rates [14]. Reference [15] combined the electric model developed in [10] and thermal model developed in [14] to derive a thermoelectric analytical model. This model can inspect the behavioral change of battery due to temperature variation, but contains others lacking in [10].

For online SOC estimation, [16] proposes the model with internal resistance, $\mathrm{OCV}$, and two RC circuit combinations. For SOC estimation they considered only coulomb counting and neglected voltage based counting which is required for better accuracy. The model developed in [17] is a blend of previous models and overcomes few of their limitations. It predicts runtime, steady state, and transient response accurately by capturing all the dynamic electrical characteristics of batteries. The RC network is modeled to account the effect of self-discharge losses due to long time storage and also includes transient response but it does not include thermal effects. Reference [18] used a model developed in [17] and incorporated temperature and capacity fading effect, to propose a dynamic model of Li-ion battery using MATLAB/Simulink. To determine online SOC of Li-ion battery, [19] estimated electrical parameters with temperature variation. Determination of battery SOC using a secondorder model is introduced in $[16,20]$.

Kroeze and Krein proposed two models for predicting SOC, terminal voltage, and power losses. These are the following: (1) SOC can be predicted when temperature and cycle number are given and (2) transient behavior of terminal voltage can be figured out where each parameter is a function of SOC [21]. Zhang and Chow constructed an equivalent circuit of battery cell which is based on Thevenin's theorem. It describes the SOC variation with current and considers the battery relaxation effect too but lacks online-parameter variation which is important in $\mathrm{HEV} / \mathrm{PHEV}$ applications [22]. This also neglects self-discharge current which results in an approximate error of $3 \%$ between experimental and estimated SOC. Randles' model [23] developed for lead-acid batteries is remapped by Gould et al. [24]. They implemented an equivalent circuit model to determine state of function of Li-ion battery but did not consider the temperature effect. Based on experimental results, 2RC battery model is proposed and mathematical modeling is performed in [25], but self-discharge current is not discussed. References [2628] also proposed 2RC battery model, but no discussion of self-discharge current is performed. Reference [29] has also used 2RC battery model and temperature effect is also incorporated, but again self-discharge current is not discussed.

A large number of researchers attempted to calculate exact SOC of the battery. Pang et al. [30] used OCV method to calculate the SOC (voltage based SOC, i.e., $\mathrm{SOC}_{v}$ ) of the battery. The OCV based SOC estimation technique is advantageous in various aspects as follows: (i) OCV versus SOC characteristic is independent of the age of the $\mathrm{Li}$-ion battery [31] and (ii) this is very accurate but requires some rest time [32]. Ampere-hour counting method (current based $\mathrm{SOC}$, i.e., $\mathrm{SOC}_{i}$ ) is a suitable method to estimate $\mathrm{SOC}$ of the battery as it is easy, direct, and easily implementable. If the current measurement is accurate, then the method is also reliable. But it may have some initial value or accumulated error problems [33]. To overcome the shortcomings of both 
and to utilize the added advantages, these two methods can be combined together. References $[19,34]$ identified the contribution of both $\mathrm{SOC}_{v}$ and $\mathrm{SOC}_{i}$ together to estimate accurate SOC of the battery but do not include the effects of temperature.

\section{Proposed Model}

The proposed model considers the effects of temperature as an independent variable and incorporates self-discharge current as well in calculations. The objective is to model a Li-ion battery to represent its actual characteristics to achieve high accuracy and robustness in run-time SOC estimation. The model is aimed to simulate the dynamic behavior of a Li-ion battery as a second-order equivalent circuit in SIMULINK. All the parameters in the proposed model are multivariable functions of the SOC, current, and temperature.

3.1. SOC Estimation. It is appreciable to characterize the Liion battery to dynamically compute the SOC even in case of temperature variation. Li-ion battery has a very eminent effect of temperature on its performance and various parameters. Under optimal temperature range batteries behave as prescribed, but outside battery cell experiences severe loss of capacity. To characterize the battery performance under the influence of temperature, thermal effect during modeling is deemed. Temperature dependent modeling provides the pertinent information about the parameters under temperature variation.

The vehicle performance is characterized by SOC of battery defined as the ratio of remaining capacity to fully charged capacity:

$$
\mathrm{SOC}=\mathrm{SOC}_{0}-\frac{1}{\mathrm{SOC}_{0}} \int i d t
$$

$\mathrm{SOC}_{0}$ is the initial SOC level of battery.

3.1.1. $\mathrm{SOC}_{v}$ Calculation. Cell voltage under reversible conditions, that is, all the reactions are balanced, is called equilibrium voltage which is occasionally referred to as OCV or rest voltage. With this $\mathrm{OCV}$, voltages based SOC $\left(\mathrm{SOC}_{v}\right)$ can be estimated using

$$
\mathrm{SOC}_{v}=\frac{1}{a_{1}}\left(\mathrm{OCV}-a_{0}\right),
$$

where $a_{0}$ is battery terminal voltage when SOC $=0 \%$ and $a_{1}$ is battery terminal voltage when $\mathrm{SOC}=100 \%$. But, due to change in temperature, equilibrium voltage of battery at any temperature $T$ gets changed as

$$
V_{(T)}=V_{(298)}+\left(\frac{d V}{d T}\right)(T-298) \Longrightarrow \mathrm{OCV}
$$

$d V / d T$ is temperature coefficient and is constant for the considered temperature range. So the consideration of this $\mathrm{OCV}$ with temperature effect will lead to modifying $\mathrm{SOC}_{v}$ and will contribute in the final SOC calculation.
3.1.2. $S \mathrm{CC}_{i}$ Calculation. The coulomb counting method involves the current integration flowing through the battery to get $\mathrm{SOC}_{i}$ :

$$
\mathrm{SOC}_{i}=\frac{1}{C_{p}}\left(C_{p}-\int i d t\right) .
$$

$C_{p}$ is battery capacity in Ah. Due to change in temperature, the cell reaction rate gets changed which has been depicted here using (5), (6), and (7). From the Arrhenius equation, the reaction rate is given as

$$
K=K_{0} * e^{\left(-E_{a} / R T\right)} .
$$

$K_{0}$ is reaction constant, $R$ is gas constant, $E_{a}$ is activation energy, and $T$ is operating temperature. During the electron transfer reaction, electrons require the additional amount of energy to surmount the energy barrier called the activation energy $\left(E_{a}=\mathrm{J} \cdot \mathrm{mol}^{-1}\right)$ which depends on temperature. As for every $10^{\circ} \mathrm{C}$ temperature increase, current gets doubled so for $\Delta T$ temperature change, reaction rate ratio is articulated as

$$
\frac{K(T+\Delta T)}{K(T)}=2^{(\Delta T / 10)} \text {. }
$$

$K$ is the reaction rate (mole/s) and can be expressed as current. Suppose $K_{1}$ is the reaction rate at a temperature $(T+\Delta T)$, that is, $K_{1}=K(T+\Delta T)$, and $K_{2}$ at temperature $T$, that is, $K_{2}=K(T)$. To represent the effect of temperature on $E_{a},(5)$ and (6) are equated as (7) and hence $E_{a}$ is presented as (8):

$$
\begin{aligned}
\ln \frac{K(T+\Delta T)}{K(T)} & =\frac{E_{a}}{R}\left(\frac{1}{T_{T}}-\frac{1}{T_{(T+\Delta T)}}\right)=\left(\frac{\Delta T}{10}\right) \ln 2, \\
E_{a} & =\ln 2\left(\frac{R}{10}\right)(T *(T+10)) .
\end{aligned}
$$

Li-ion batteries exhibit self-discharge phenomenon even at moderate oxidation levels. It is primarily due to loses occurring at the negative electrode, which results from several side reactions, each with their own activation energy and rate constant. From Arrhenius equation self-discharge current can also be modeled as (5). The battery capacity also affects it; hence self-discharge current is sculpted as (9) considering the effect of temperature on activation energy from (8):

$$
I_{(\mathrm{s}-\mathrm{d})}=\frac{1}{c_{p}} K_{0}(T) e^{-(\ln 2(R / 10)(T *(T+10)))} .
$$

3.1.3. Modified SOC Calculation. Temperature dependent SOC can be deduced as (10) by combining $\mathrm{SOC}_{v}$ and $\mathrm{SOC}_{i}$ with a weighting factor $w$. Charging and discharging efficiency influence battery dynamics to a great extent; weighting factor allied with $\mathrm{SOC}_{i}$ should govern the combined SOC. Correction factor (CF) $\eta$ is integrated here, which is a function of SOC as (11) which helps in getting exact SOC during discharging:

$$
\begin{aligned}
\mathrm{SOC} & =w \mathrm{SOC}_{v}+(1-w)\left(\mathrm{SOC}_{i}-\eta\right), \\
\eta & =\left(1-\frac{\mathrm{SOC}_{0}}{100}\right)
\end{aligned}
$$


TABLE 1: Values of $w,(1-w)$, and $\eta$ respective to the SOCs.

\begin{tabular}{lccccccccccccc}
\hline SOC (\%) & 100 & 90 & 80 & 70 & 60 & 50 & 40 & 30 & 20 & 10 & 0 \\
\hline$w$ & 0.042 & 0.034 & 0.025 & 0.0171 & 0.0085 & 0 & 0.0085 & 0.0171 & 0.025 & 0.034 & 0.0428 \\
\hline $1-w$ & 0.958 & 0.960 & 0.975 & 0.9829 & 0.9915 & 1 & 0.9915 & 0.9829 & 0.975 & 0.966 & 0.9571 \\
\hline$\eta$ & 0 & 0.1 & 0.2 & 0.3 & 0.4 & 0.5 & 0.6 & 0.7 & 0.8 & 0.9 & 1 \\
\hline
\end{tabular}

3.2. Weighting Factor Calculation. To calculate the weighting factor, the value of OCV and time required to get steady OCV should be considered because under steady condition $\mathrm{SOC}_{v}$ has higher accuracy. The entire OCV range is divided into 100 sections; each section weighting value is calculated as

$$
w_{1}=2 *|k-50| * \frac{0.5}{100} ; \quad 1 \leq k \leq 100 .
$$

According to experimental data, average time taken by OCV to get steady condition is $t_{s}=1278 \mathrm{~s}$ and time between two samples is $t=192.78 \mathrm{~s}$. As $t<t_{s}$, weighting factor $w$ is deduced as (13). Table 1 lists the values of weighting factors and correction factor at various SOC levels:

$$
w=w_{1} * \frac{t}{t_{s}}
$$

Table 2 brings together the expected SOC values to be generated during discharging and values obtained from simulation. The modified SOC estimation method calculates (very nearby) expected values from the range of $100 \%$ to $50 \%$. The error is very less in the range of $0-0.5 \%$. From $50-36 \%$ SOC ranges, the error between the expected and obtained SOC is lesser than $2 \%$, but error starts increasing $35 \%$ onward and continues to empty state.

3.3. Correction Factor Determination. Determining CF is an essential and more intricate process. Since the battery provides electrical energy to the load (vehicle), more precise SOC estimation is a very important consideration under dynamic state of charge/discharge for the driver and vehicle controller. Over the time sphere, under various operational conditions, the current transfer rate affects the CF so it is closely related to the charge/discharge rate. Battery performance is expected to get varied with the load; and CF gets modified for the varying conditions. CF at the fixed temperature is a function of SOC. Reference [35] substantiates variation of CF with SOC and temperature and justifies it with the mathematical expression derived. When battery alone is considered, then CF can be estimated as (11) but as it gets associated with the load it varies significantly and can alter the performance of the vehicle.

At high SOC levels, the kinetic rates are high in the presence of more unreacted active mass and existence of higher level of electrolyte concentration which leads to rapid material conversion. At low SOC levels, the kinetic rates are relatively low and lead to $100 \%$ charge efficiency [36]. Change in temperature directly influences the rate of reaction and hence governs CF. So, CF is a function of temperature $T$ and SOC and demonstrated by the simulation results. CF derived can be stored or calculated "on-the-fly" and applied incrementally to correct the SOC. The CF variation with the SOC and temperature is shown in Figure 1.
TABLE 2: Comparison between expected and obtained values of SOCs.

\begin{tabular}{lcc}
\hline Expected SOC (\%) & Obtained SOC (\%) & Error $(\%)$ \\
\hline 100 & 100 & 0 \\
90 & 90.09 & 0.1 \\
80 & 80.32 & 0.4 \\
70 & 70.39 & 0.5571 \\
60 & 60.28 & 0.4667 \\
50 & 50 & 0 \\
40 & 40.44 & 1.1 \\
39 & 39.5 & 1.2821 \\
38 & 38.55 & 1.4474 \\
37 & 37.61 & 1.6486 \\
36 & 36.67 & 1.8611 \\
35 & 35.73 & 2.0857 \\
34 & 34.79 & 2.3235 \\
33 & 33.85 & 2.5758 \\
32 & 32.92 & 2.875 \\
31 & 31.99 & 3.1935 \\
30 & 31.05 & 3.5 \\
20 & 21.82 & 9.1 \\
10 & 12.68 & 26.8 \\
0 & $1.07 e-07$ & 0 \\
\hline
\end{tabular}

Exploration of $\mathrm{CF}$ for the range of SOCs with wide temperature series is performed, that is, $0^{\circ} \mathrm{C}, 25^{\circ} \mathrm{C}, 50^{\circ} \mathrm{C}$, and $60^{\circ} \mathrm{C}$ (very low, room, and high temperatures), which helps to find a healthy operating range of the battery. The pattern achieved is nearby Cauchy's distribution. At room temperature $\left(25^{\circ} \mathrm{C}\right), \mathrm{CF}$ is higher at lower SOCs and gets low down with the higher SOC values. The same pattern is observed for the $0^{\circ} \mathrm{C}, 50^{\circ} \mathrm{C}$, and $60^{\circ} \mathrm{C}$; only the quantitative measures are changed. Estimate the $\mathrm{CF}$ at room temperature and store the values in look-up table. According to the developed relation as given in (14), CFs are calculated "onthe-fly" at various SOCs and temperatures onwards. $\varepsilon$ is the error tolerance, applicable in the cases of temperature variation:

$$
\eta_{\text {new }(T, S O C)}=\eta_{298}+\frac{(\mathrm{SOC} / 1000)}{T-298} \pm \varepsilon
$$

3.4. Proposed SOC Estimation Algorithm. Continuous recording of SOC during vehicle propulsion is important to update power management system. The power management system, then, takes decision to toggle between battery and engine for minimum fuel consumption and better energy efficiency. Change in temperature due to any reason (environmental 


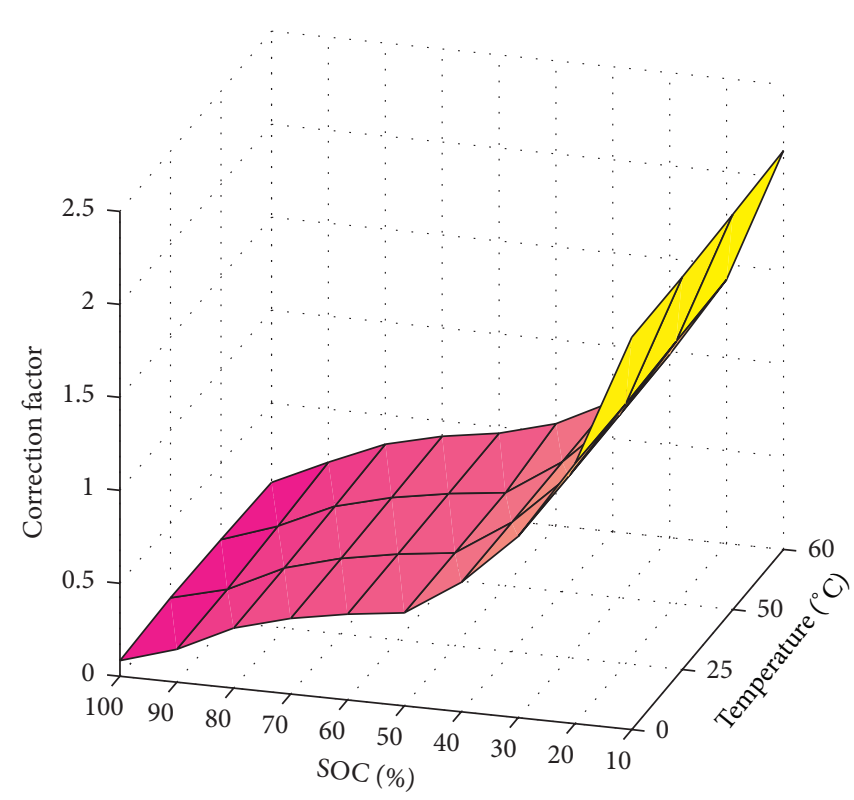

FIGURE 1: Correction factor variation with temperature and SOC.

effect or battery pack utilization) alters the characteristic of the battery. Self-discharge current and effect of temperature change are considered in the proposed algorithm. Flow chart of the proposed algorithm is shown in Figure 2. The simulation data are analyzed to obtain the effect of temperature on open circuit voltage, SOC, resistance, and capacity of battery.

\section{Development of Proposed Thermoelectric Model}

In a Li-ion battery, Li-ions move from anode to cathode through an organic electrolyte during discharging. During charging the reverse process is followed. Anode and cathode have layered structure and $\mathrm{Li}$-ions move in between layers. The governing chemical reactions are as follows:

$$
\begin{aligned}
& \text { Cathode: } \mathrm{Li}_{1-x} \mathrm{CoO}_{2}+x \mathrm{Li}^{+}+x \mathrm{e}^{-} \rightarrow \mathrm{LiCoO}_{2} \\
& \text { Anode: } \mathrm{Li}_{x} \mathrm{C}_{6} \rightarrow x \mathrm{Li}^{+}+x \mathrm{e}^{-}+6 \mathrm{C}
\end{aligned}
$$

The time varying response of battery can be represented by a combination of diffusion and double layer resistance and capacitances [37, 38]. Proposed battery model is shown in Figure 3, where $V$ is the voltage source which is a function of charge remaining in the battery, $R_{\text {int }}$ is internal resistance, and $R_{1}, R_{2}, C_{1}$, and $C_{2}$ are diffusion and double layer resistances, and capacitances, respectively. The output voltage of the battery is lower than no load voltage due to voltage drop and is represented as $R_{\text {int }}$.

Temperature effect and self-discharge current are included for analyzing run-time characteristics. A number of Li-ion cells are connected in series and in parallel to simulate a powerful battery to be used in hybrid vehicles. The output voltage is calculated as (15) where $V(t)$ is time dependent OCV, $i(t)$ is the time dependent current, and multiplier term associated with $i(t)$ represents the impedance offered.
From (2), temperature dependent voltage based SOC, that is, $\operatorname{SOC}_{v}(T)$, can be intended as (16) and from (4) temperature dependent current based SOC, that is, $\operatorname{SOC}_{i}(T)$, can be calculated as (17):

$$
\begin{aligned}
& V^{\prime}(t)=V(t)-i(t)\left[R_{\mathrm{int}}-\left\{\left(\frac{R_{1}+2 R_{\mathrm{int}}}{R_{1} C_{1}}\right) e^{-\left(t / R_{1} C_{1}\right)}\right\}\right. \\
& \left.-\left\{\left(\frac{R_{2}+2 R_{\mathrm{int}}}{R_{2} C_{2}}\right) e^{-\left(t / R_{2} C_{2}\right)}\right\}\right], \\
& \operatorname{SOC}_{v}(T)=\frac{1}{a_{1}}\left[\left\{V^{\prime}(t)+\left(i(t) * 2^{(\Delta T / 10)}+I_{(\mathrm{s}-\mathrm{d})}(t)\right)\right.\right. \\
& *\left[R_{\mathrm{int}}-\left\{\left(\frac{R_{1}+2 R_{\mathrm{int}}}{R_{1} C_{1}}\right) e^{-\left(t / R_{1} C_{1}\right)}\right\}\right. \\
& \left.\left.-\left\{\left(\frac{R_{2}+2 R_{\mathrm{int}}}{R_{2} C_{2}}\right) e^{-\left(t / R_{2} C_{2}\right)}\right\}\right]\right\}+\left(\frac{d V}{d T}\right)(T-298) \\
& \left.\quad-a_{0}\right] \\
& \operatorname{SOC}_{i}(T)=\frac{1}{c_{p}}\left[c_{p}-\int\left\{i(t) * 2^{(\Delta T / 10)}+I_{(\mathrm{s}-\mathrm{d})}(t)\right\} d t\right] .
\end{aligned}
$$

SOC at (any temperature) operating temperature $T$ can be calculated using (10), (16), and (17). Electric component values are simulated and determined with varied SOC as shown in Figure 4 . The model is largely practicable because all the extracted RC parameters are approximately constant over $20 \%-100 \%$ SOC and change exponentially within the lower limits of SOC of the battery. 


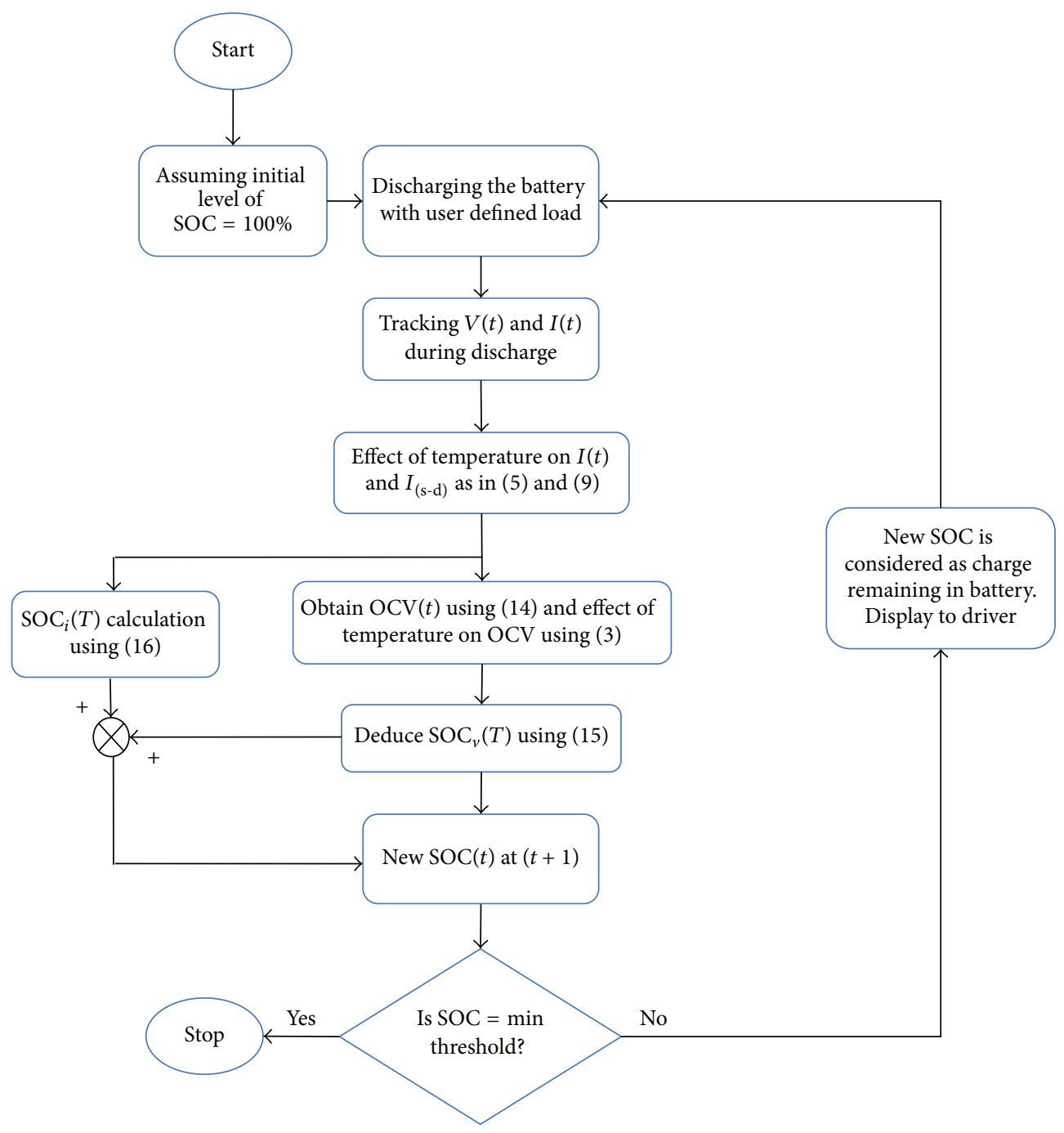

FIGURE 2: Flow diagram of online SOC estimation.

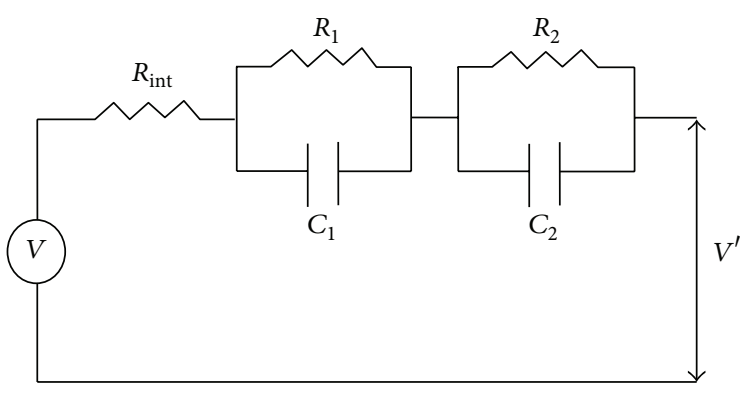

Figure 3: Thermoelectrical model.

\section{Simulation Results}

Concentration of Li-ions of solid phase with respect to intercalating material (Li-ion) represents $\mathrm{OCV}$ and gets affected by changes in chemical composition, pressure, and temperature. The proposed model is simulated in wide temperature range of $25-70^{\circ} \mathrm{C}$ and variation of OCV is intrigued with respect to SOC as shown in Figure 5. Increment in
OCV is recorded as the temperature increases from ambient and vice versa for the decrease in temperature but fluctuates roughly with temperature variation. From $20^{\circ} \mathrm{C}$ to $40^{\circ} \mathrm{C}$ curves are very close to each other, but beyond $40^{\circ} \mathrm{C} \mathrm{OCV}$ increases, which depicts the true property of the battery. While comparing with [39], at $0^{\circ} \mathrm{C}$ and $25^{\circ} \mathrm{C}$ not much variation in $\mathrm{OCV}$ is found, but a significant change at $60^{\circ} \mathrm{C}$ is observed as shown in Figures 6(a), 6(b), and 6(c). 


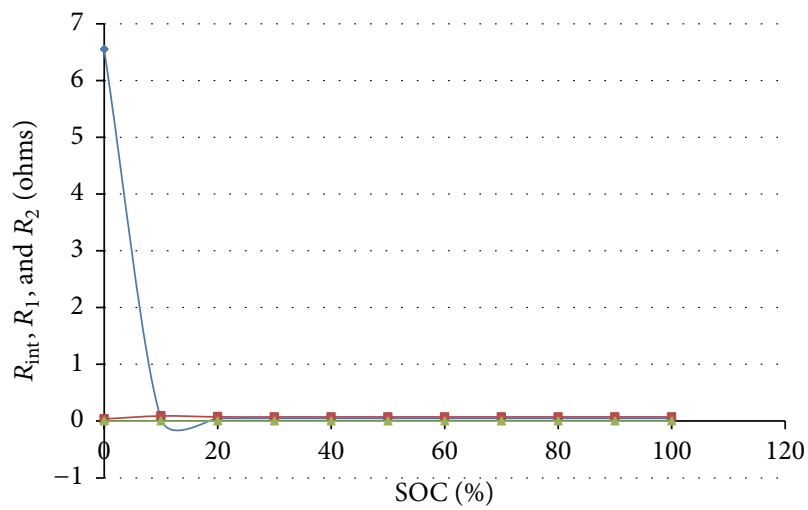

$\rightarrow R_{2}$
$\rightarrow-R_{1}$ $\rightarrow R_{\text {int }}$

(a)

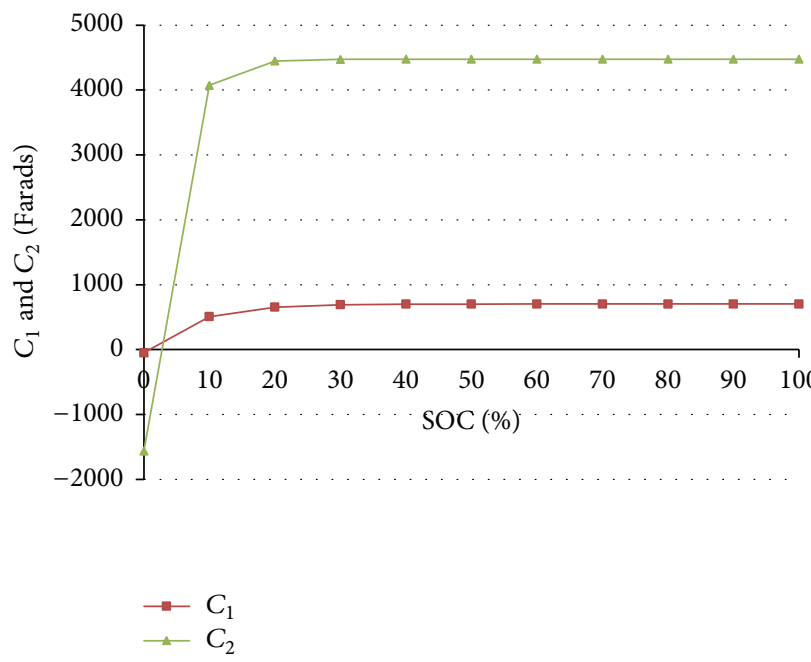

(b)

Figure 4: RC parameter variation with SOC (a) $R_{\text {int }}, R_{1}$, and $R_{2}$ and (b) $C_{1}$ and $C_{2}$.

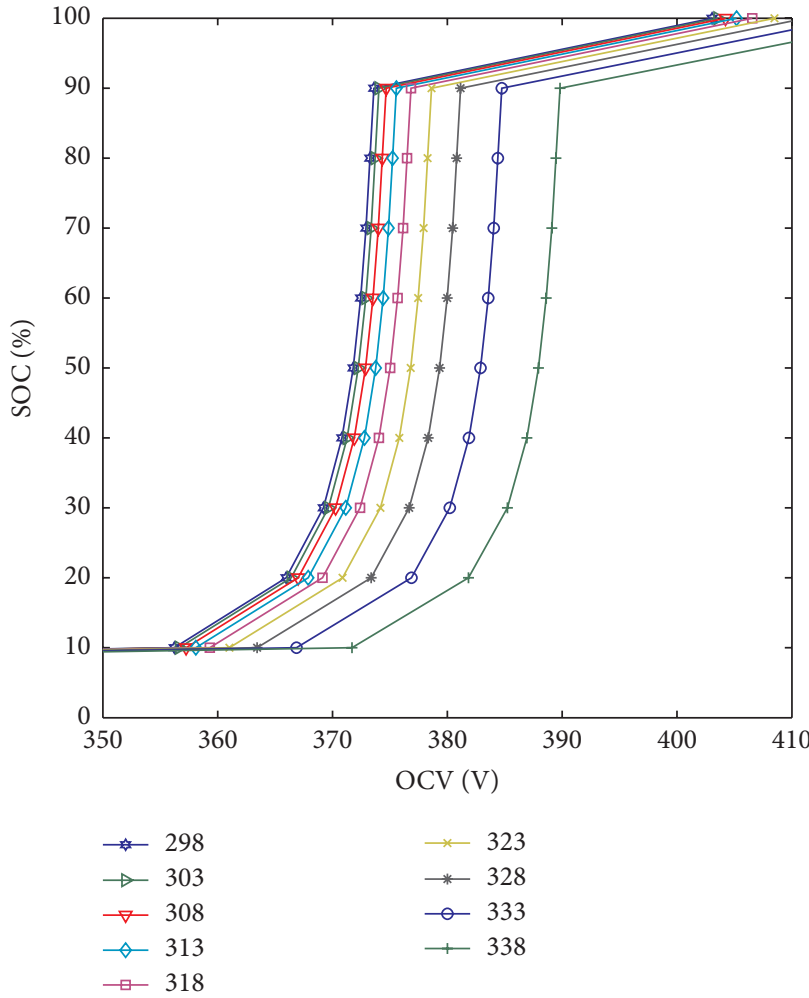

Figure 5: SOC versus OCV at different temperature.

At lower temperature, battery cell is inefficient due to more impedance, but, at higher temperature, efficiency improves because the rate of chemical reactions increases due to lesser impedance offered. With the increase in temperature, resistance decreases which is shown in Figure 7. Johnson locates an increment of three times in resistance as the temperature drops from ambient to $0^{\circ} \mathrm{C}[40]$. Johnson et al. articulate that resistance can get varied by eight times depending upon discharge rate [41]. For proposed model, it increases by 5.5 times than the ambient level as the temperature drops to the $0^{\circ} \mathrm{C}$. Battery capacity extensively varies with operating conditions and strongly depends on its internal impedance. With changing temperature, impedance of a battery varies a lot, hence capacity. At lower temperatures, cell reaction rate decreases, hence low current flows and vice versa at higher temperatures as shown in Figure 7. Therefore, usable capacity decreases at low temperatures and increases at high temperatures. At $0^{\circ} \mathrm{C}$, capacity is found to be $17.11 \%$ of 


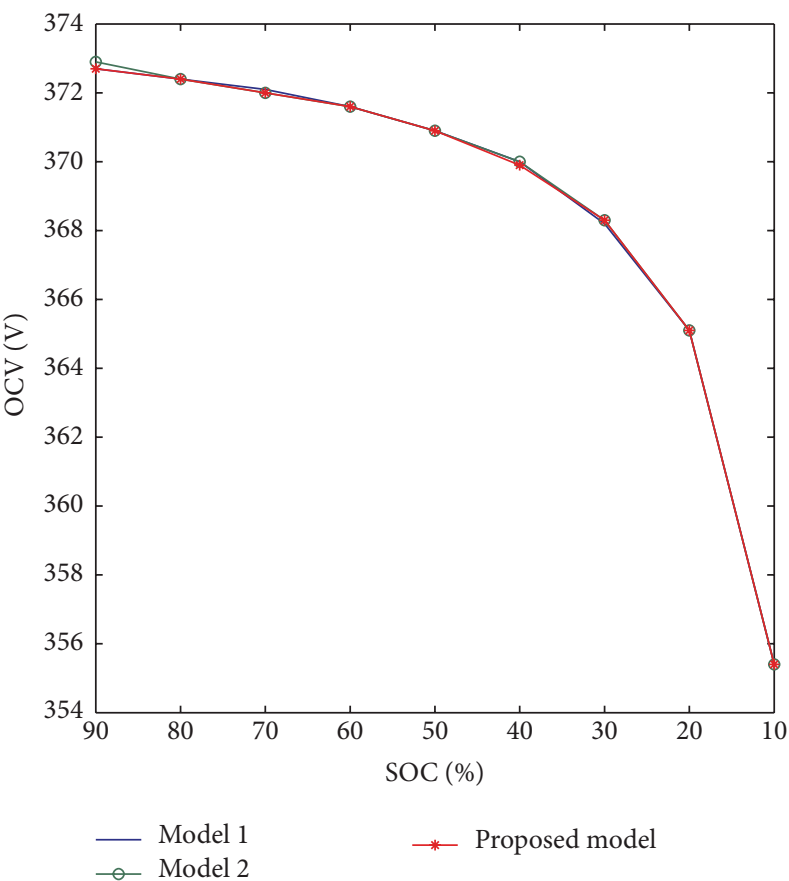

(a)

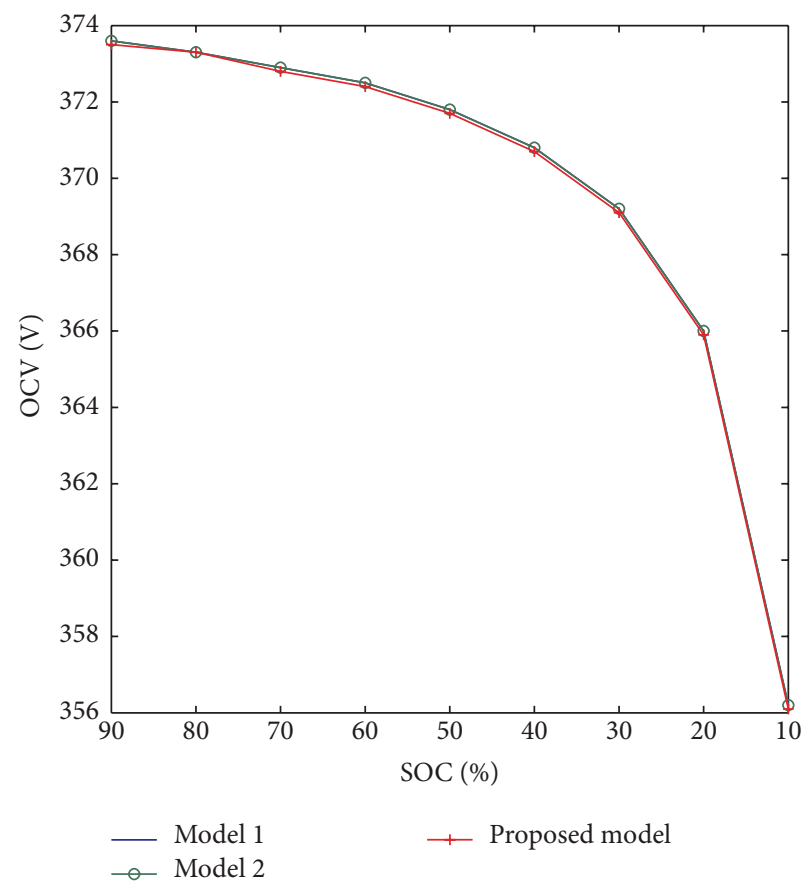

(b)

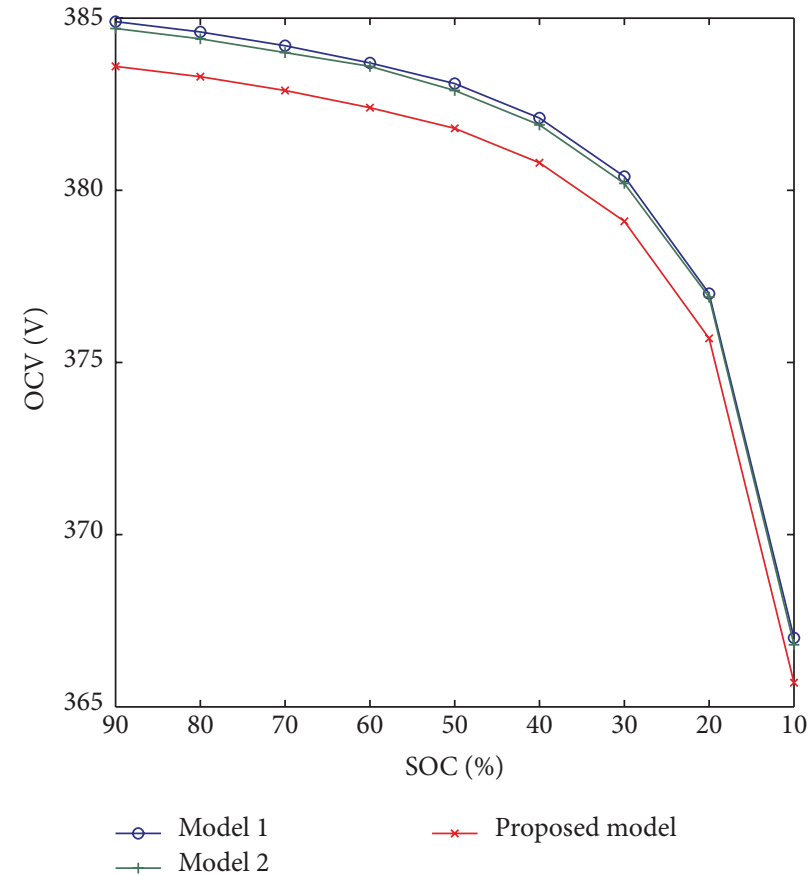

(c)

Figure 6: Temperature effect on OCV (a) at $273 \mathrm{~K}$, (b) at $298 \mathrm{~K}$, and (c) at $333 \mathrm{~K}$.

its value at ambient. At higher temperatures, current drawn from battery increases rapidly, and battery depletes swiftly. At $40^{\circ} \mathrm{C}$ the usable capacity is $5.6 \%$ more than the value at ambient. These results are better than other reported works.

For the fixed temperature, battery resistance variations are small for a complete SOC range from $100 \%$ to $10 \%$ as shown in Figure 8(a) and results are comparable with [13]. To accommodate all temperature data, a larger scale range is chosen; that is why the plots seem to be constant, but variation is observed when plotted for individual cases as shown in Figure $8(\mathrm{~b})$. The given figure represents the resistance variation on individual scales at different temperatures. This 


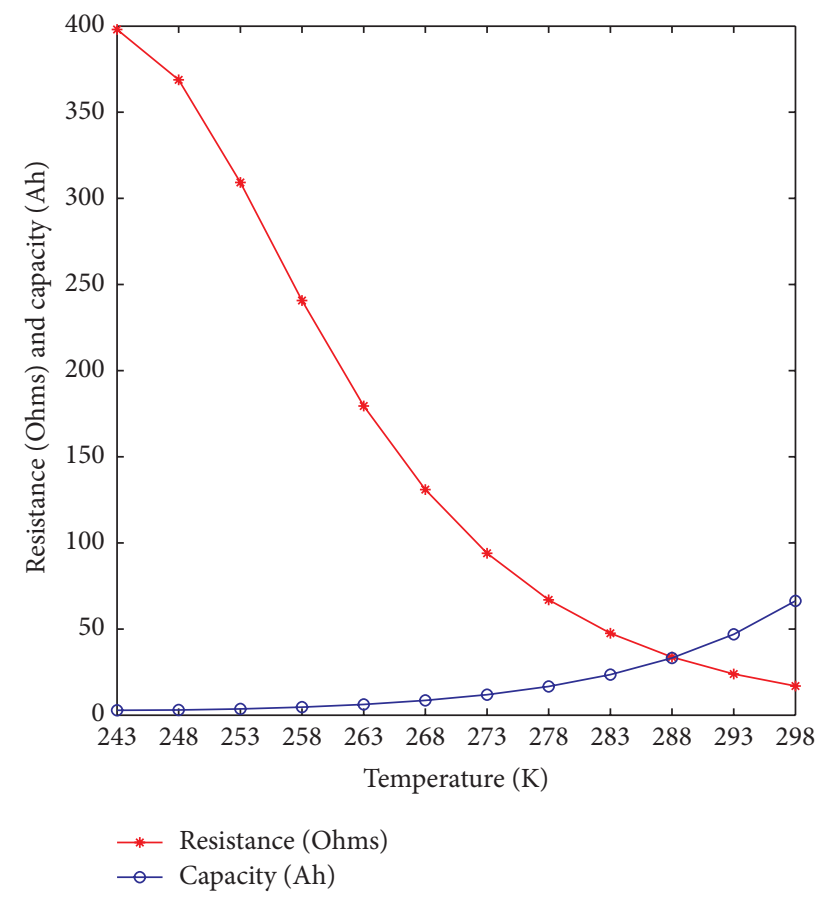

FIgURE 7: Resistance and capacity variation with temperature.

TABLE 3: Fuel economy comparison chart for SOC methods.

\begin{tabular}{lc}
\hline SOC estimation method & Fuel economy (mpgge) \\
\hline Default & 25.2 \\
\hline Modified (proposed) & 51.5 \\
\hline
\end{tabular}

change varying from $0.005 \%$ to $0.26 \%$ on $273 \mathrm{~K}$ temperature is observed. Almost the same pattern with little bit variation is observed for other temperatures as well.

Battery operation at enormously high temperatures causes an increase in rate of thermal reactions leading to even higher heat generation. Many electrochemical side reactions are damaged in the process. An efficient convective cooling system can avoid such high temperature excursions during repeated cycling.

Simulation of HEV is performed over the ECE_EUDC driving cycle and is presented separately in [30]. The authors also observed that the proposed SOC estimation method gives better fuel efficiency with $2 \mathrm{RC}$ battery model than the default SOC estimation method as shown in Table 3.

\section{Threshold SOC Determination}

Li-ion batteries are used extensively in PHEVs to propel the vehicle as primary power source; hence it is essential to monitor continuously its charge status in terms of SOC. Overcharging and depletion below a specified level deteriorates battery health. Since batteries are expensive, it is compulsory to take care of their health for durability. Battery mainly operates in two modes: (1) charge depletion and (2) charge sustaining. In Hybrid Electric Vehicles (HEVs) both modes together are used in such a way that initial and final SOC at the end of the trip are the same. In HEVs, batteries get charged either by the engine (indirectly by fuel) or by regenerative braking.

As far as PHEVs are concerned, the batteries are charged through main supply at home or parking lots; therefore it can be depleted completely at the end of the trip. However, depleting a battery below a threshold level deteriorates its health and hence performance. In available literatures, authors do not find proper justification to choose the lowest SOC level up to which battery should be allowed to discharge. Based on data collected during discharge from $100 \%$ to $0 \%$ SOC at various temperatures, the authors propose determination of the threshold SOC level using gradient method. The curves shown in Figure 5 are seventh-order equation at $25^{\circ} \mathrm{C}$ written as

$$
\begin{aligned}
\mathrm{SOC}= & p_{1} * z_{7}+p_{2} * z_{6}+p_{3} * z_{5}+p_{4} * z_{4}+p_{5} \\
& * z_{3}+p_{6} * z_{2}+p_{7} * z+p_{8},
\end{aligned}
$$

where $p_{1}=-6.9991 e+007, p_{2}=-8.6071 e+007, p_{3}=$ $2.8379 e+008, p_{4}=-2.3169 e+008, p_{5}=0.0481 e+007$, $p_{6}=1.8831 e+007, p_{7}=2.0122 e+006, p_{8}=-86693$, and $z$ is $\mathrm{OCV}$.

SOC from $90 \%$ to $35 \%$ gives almost constant OCV and hence this range is the best for vehicle propulsion. Below 35\%, a rapid decline is observed. Values also get authenticated from Table 2. Proposed threshold level of SOC is 35\% and operating under this is not recommended as exposed in Figure 9. Operating a battery at higher temperatures, threshold occurs sooner and at lower temperatures it occurs later as compared to the room temperature case, which can also be surveyed in Figure 5.

\section{Conclusion}

Today, the major challenge is to utilize battery power efficiently without affecting its health to minimize the fuel consumption in PHEVs. The authors proposed a $2 \mathrm{RC}$ battery model, for HEV/PHEV applications. They have included temperature and self-discharge current both while modeling in Simulink and developing mathematical expressions. Along with this, the authors used both open circuit voltage and coulomb counting method together to estimate battery SOC. This SOC estimation was further improved using a correction factor. Since battery performance greatly depends on temperature, a generalized thermoelectric model is proposed to characterize its dynamics.

Effect of temperature on various parameters like current, $\mathrm{OCV}$, capacity, and resistance is determined. It is observed that, from $0^{\circ} \mathrm{C}$ to $40^{\circ} \mathrm{C}$, OCV values do not vary much, but beyond this they get amplified because of transient effects. Higher resistance at and below room temperature and a lesser amount of offered resistance beyond room temperature are demonstrated. Hence, capacity becomes very high at higher temperature, but at the same time current drawn from the battery turns out to be high; consequently, battery depletes rapidly. The online estimation of SOC is carried out to use the battery power judiciously; in addition, a threshold SOC, that 


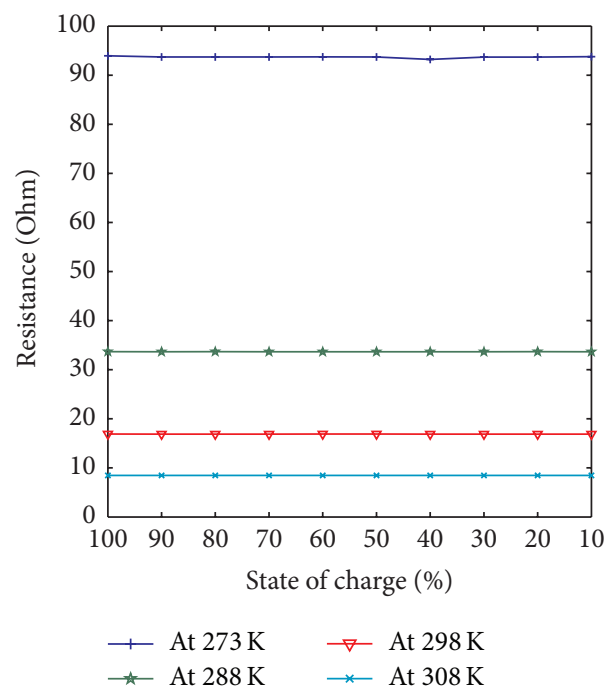

(a)
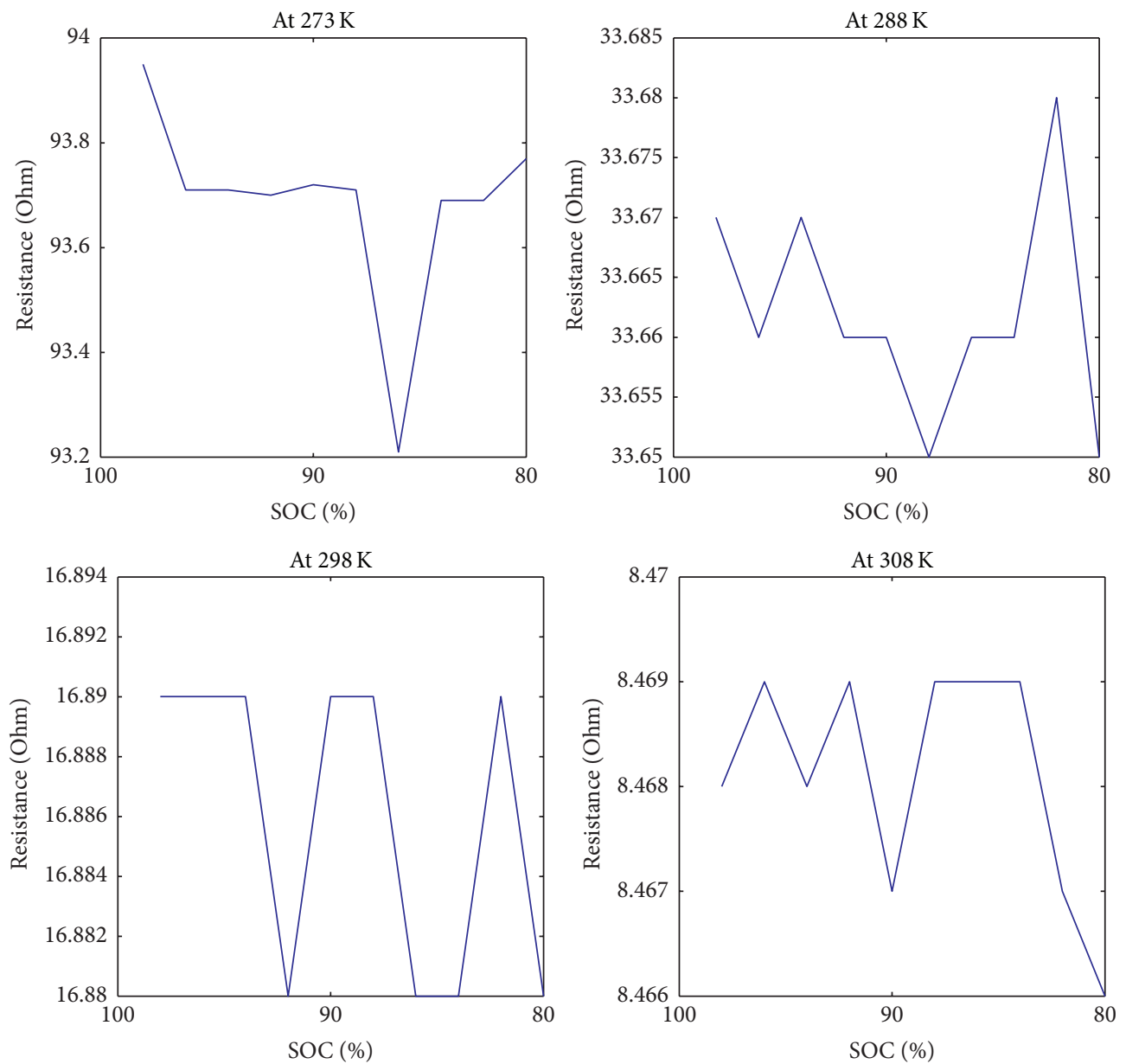

(b)

FIGURE 8: Resistance variation with varying SOC; (a) all temperatures in same plot and (b) plots for individual temperature. 


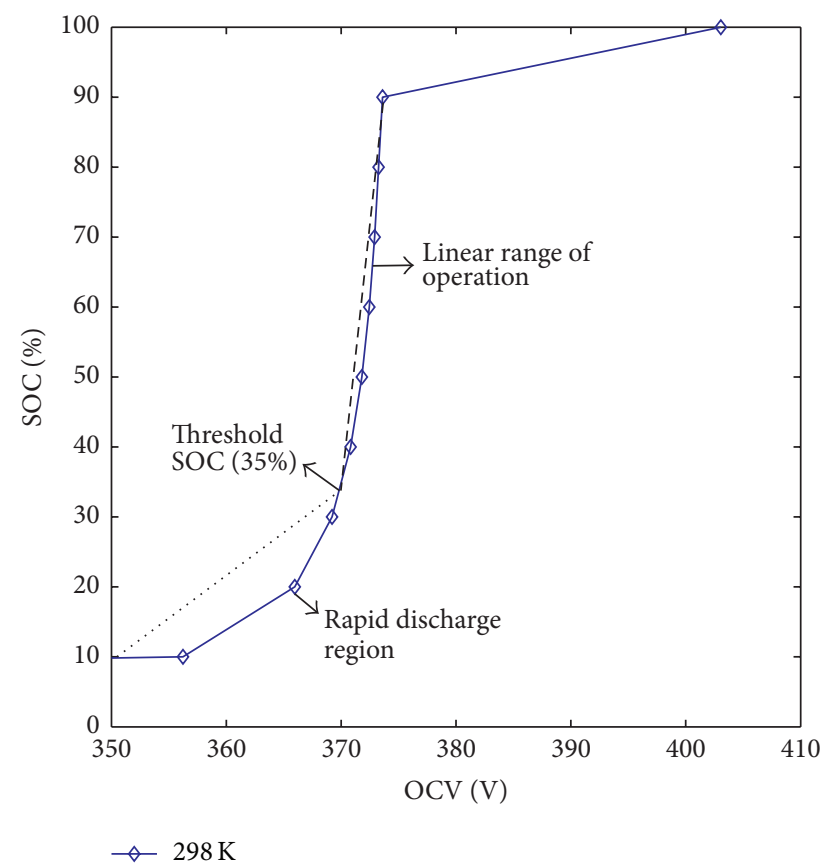

FIGURE 9: Determination of threshold SOC.

is, $35 \%$, is gauged and suggests not to use the battery below this threshold due to health reasons.

\section{Conflict of Interests}

The authors declare that there is no conflict of interests regarding the publication of this paper.

\section{Acknowledgments}

The authors are grateful to Dr. V. S. Nirban and Dr. Navneet Gupta for their significant contribution in revising the paper.

\section{References}

[1] K. Parks, P. Denholm, and T. Markel, "Costs and emissions associated with plug-in hybrid electric vehicle charging in the xcel energy Colorado service territory," Tech. Rep. NREL/TP-64041410. Contract no. DE-AC36-99-GO10337, National Renewable Energy Laboratory, 2007.

[2] M. Wakihara, "Recent developments in lithium ion batteries," Materials Science and Engineering, vol. 33, no. 4, pp. 109-134, 2001.

[3] X. Zhang and C. Mi, "Modeling of vehicle propulsion systems," in Vehicle Power Management, chapter 3, pp. 49-105, Springer, London, UK, 2011.

[4] L. Lam, A practical circuit based model for state of health estimation of li-ion [M.S. thesis], Department of Electrical Sustainable Energy, Delft University of Technology, Delft, The Netherlands, 2011.

[5] G. Sean, A PSPICE Macromodel for Lithium-Ion Batteries, PolyStor Corporation, Dublin, Calif, USA, 1997.

[6] L. Benini, G. Castelli, A. Macii, E. Macii, M. Poncino, and R. Scarsi, "Discrete-time battery models for system-level lowpower design," IEEE Transaction on Very Large Scale Integration System, vol. 9, no. 5, pp. 630-640, 2001.
[7] A. A. Pesaran, V. H. Johnson, and T. Sack, "Temperaturedependent battery models for high-power lithium-ion batteries," Tech. Rep. NREL/CP-540-28716, Contract no. DEAC36-99GO10337, Midwest Research Institute, US Government, Kansas City, Mo, USA, 2001.

[8] S. X. Chen, K. J. Tseng, and S. S. Choi, "Modeling of lithiumion battery for energy storage system simulation," in Proceedings of the Asia-Pacific Power and Energy Engineering Conference (APPEEC '09), pp. 1-4, IEEE, Wuhan, China, March 2009.

[9] L. Gao, S. Liu, and R. A. Dougal, "Dynamic lithium-ion battery model for system simulation," IEEE Transactions on Components and Packaging Technologies, vol. 25, no. 3, pp. 495505, 2002.

[10] O. Tremblay, L.-A. Dessaint, and A.-I. Dekkiche, "A generic battery model for the dynamic simulation of hybrid electric vehicles," in Proceedings of the IEEE Vehicle Power and Propulsion Conference (VPPC '07), pp. 284-289, IEEE, Arlington, Va, USA, September 2007.

[11] S. Lee, J. Kim, J. Lee, and B. H. Cho, "State-of-charge and capacity estimation of lithium-ion battery using a new opencircuit voltage versus state-of-charge," Journal of Power Sources, vol. 185, no. 2, pp. 1367-1373, 2008.

[12] J.-S. Koo, S. S. Park, K.-Y. Youn, and C. S. Kim, "Development of SOC estimation logic using the steady state DC-IR for SHEV," in Proceedings of the 8th Electric Vehicles Symposium, Berlin, Germany, 2001.

[13] J. Kim, S. Lee, and B. Cho, "The state of charge estimation employing empirical parameters measurements for various temperatures," in Proceedings of the IEEE 6th International Power Electronics and Motion Control Conference (IPEMC '09), pp. 939-944, IEEE, Wuhan, China, May 2009.

[14] S. Bhide and T. Shim, "Development of improved Li-ion battery model incorporating thermal and rate factor effects," in Proceedings of the 5th IEEE Vehicle Power and Propulsion Conference (VPPC '09), pp. 544-550, Dearborn, Mich, USA, September 2009.

[15] Y. K. Tan, J. C. Mao, and K. J. Tsen, "Modelling of battery temperature effect on electrical characteristics of Li-ion battery in hybrid electric vehicle," in Proceedings of the 9th IEEE International Conference on Power Electronics and Drive Systems (PEDS '11), pp. 637-642, IEEE, Singapore, December 2011.

[16] H. Dai, Z. Sun, and X. Wei, "Online SOC estimation of highpower lithium-ion batteries used on HEVs," in Proceedings of the IEEE International Conference on Vehicular Electronics and Safety (ICVES '06), pp. 342-347, IEEE, Beijing, China, December 2006

[17] M. Chen and G. A. R. Mora, "Accurate electrical battery model capable of predicting runtime and I-V performance," IEEE Transactions on Energy Conversion, vol. 21, no. 2, pp. 504-511, 2006.

[18] O. Erdinc, B. Vural, and M. Uzunoglu, "A dynamic lithiumion battery model considering the effects of temperature and capacity fading," in Proceedings of the International Conference on Clean Electrical Power (ICCEP '09), pp. 383-386, IEEE, Capri, Italy, June 2009.

[19] X. Tang, X. Mao, J. Lin, and B. Koch, "Li-ion battery parameter estimation for state of charge," in Proceedings of the American Control Conference (ACC '11), pp. 941-946, IEEE, San Francisco, Calif, USA, July 2011.

[20] W. Xuezhe, Z. Guangnan, and S. Zechang, "Modeling and parameter estimation of Li-ion battery in a fuel cell vehicle," Chinese Journal of Power Sources, vol. 28, pp. 605-608, 2004. 
[21] R. C. Kroeze and P. T. Krein, "Electrical battery model for use in dynamic electric vehicle simulations," in Proceedings of the Power Electronics Specialists Conference (PESC '08), pp. 13361342, IEEE, Rhodes, Greece, June 2008.

[22] H. Zhang and M.-Y. Chow, "Comprehensive dynamic battery modeling for PHEV applications," in Proceedings of the Power and Energy Society General Meeting, pp. 1-6, IEEE, Minneapolis, Minn, USA, July 2010.

[23] K. J. Vetter, Elektrochemische Kinetik, Springer, Berlin, Germany, 1961.

[24] C. Gould, J. Wang, D. Stone, and M. Foster, "EV/HEV Liion battery modelling and State-of-Function determination," in Proceedings of the 21st IEEE International Symposium on Power Electronics, Electrical Drives, Automation and Motion (SPEEDAM '12), pp. 353-358, IEEE, Sorrento, Italy, June 2012.

[25] B. J. Yurkovich, Electrothermal battery pack modeling and simulation [M.S. thesis], The Ohio State University, 2010, Challenges.

[26] S. Thanagasundram, R. Arunachala, K. Makinejad, T. Teutsch, and A. Jossen, "A cell level model for battery simulation," in Proceedings of the European Electric Vehicle Congress (EEVC'12), pp. 1-13, Brussels, Belgium, November 2012.

[27] M. Esfahanian, A. Mahmoodian, M. Amiri et al., "Large lithium polymer battery modeling for the simulation of hybrid electric vehicles using the equivalent circuit method," International Journal of Automotive Engineering, vol. 3, no. 4, pp. 564-576, 2013.

[28] C. Zhang, J. Liu, S. M. Sharkh, and C. Zhang, "Identification of dynamic model parameters for lithium-ion batteries used in hybrid electric vehicles," in Proceedings of the International Symposium on Electric Vehicles (ISEV '09), pp. 1-11, Beijing, China, September 2009.

[29] R. K. Junnuri, S. Kamat, N. Goyal et al., "Modelling of HEV lithium-ion high voltage battery pack using dynamic data," in Proceedings of the 19th IFAC World Congress, no. 1, Cape Town, South Africa, August 2014.

[30] S. Pang, J. Farrell, J. Du, and M. Barth, "Battery state-of-charge estimation," in Proceedings of the American Control Conference, vol. 2, pp. 1644-1649, Arlington, Va, USA, June 2001.

[31] S. Abu-Sharkh and D. Doerffel, "Rapid test and non-linear model characterisation of solid-state lithium-ion batteries," Journal of Power Sources, vol. 130, no. 1-2, pp. 266-274, 2004.

[32] S. J. Lee, J. H. Kim, J. M. Lee, and B. H. Cho, "The state and parameter estimation of li-ion battery using a new OCV-SOC concept," in Proceedings of the 2007 Power Electronics Specialists Conference, pp. 2799-2803, Orlando, Fla, USA, June 2007.

[33] S. Piller, M. Perrin, and A. Jossen, "Methods of state of charge determination and their applications," Journal of Power Sources, vol. 96, no. 1, pp. 113-120, 2001.

[34] M. Verbrugge and E. Tate, "Adaptive state of charge algorithm for nickel metal hydride batteries including hysteresis phenomena," Journal of Power Sources, vol. 126, no. 1-2, pp. 236-249, 2004.

[35] A. Panday and H. O. Bansal, "Hybrid electric vehicle performance analysis under various temperature conditions," Energy Procedia, vol. 75, pp. 1962-1967, 2015.

[36] W. Y. Kwok, "Method of calculating dynamic state-of-charge within a battery," U.S. Patent 2011; 6300763 B1, 2011.

[37] E. Cliffs, Electrochemical Systems, Prentice-Hall, 2nd edition, 1991.

[38] B. E. Conway, "Transition from 'supercapacitor' to 'battery' behavior in electrochemical energy storage," Journal of the Electrochemical Society, vol. 138, no. 6, pp. 1539-1548, 1991.
[39] A. Panday and H. O. Bansal, "Temperature dependent circuitbased modeling of high power Li-ion battery for plug-in hybrid electrical vehicles," in Proceedings of the International Conference on Advances in Technology and Engineering (ICATE '13), pp. 1-6, IEEE, Mumbai, India, January 2013.

[40] V. H. Johnson, "Battery performance models in ADVISOR," Journal of Power Sources, vol. 110, no. 2, pp. 321-329, 2002.

[41] V. H. Johnson, A. A. Pesaran, and T. Sack, "Temperaturedependent battery models for high-power lithium-ion batteries," in Proceedings of the 17th Annual Electric Vehicle Symposium, Report no.: NREL/CP-540-28716, Montreal, Canada, October 2000. 


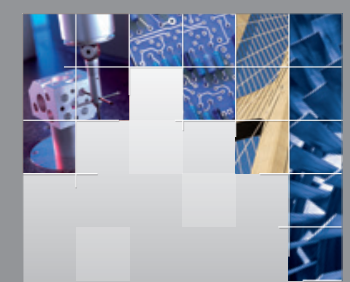

\section{Enfincering}
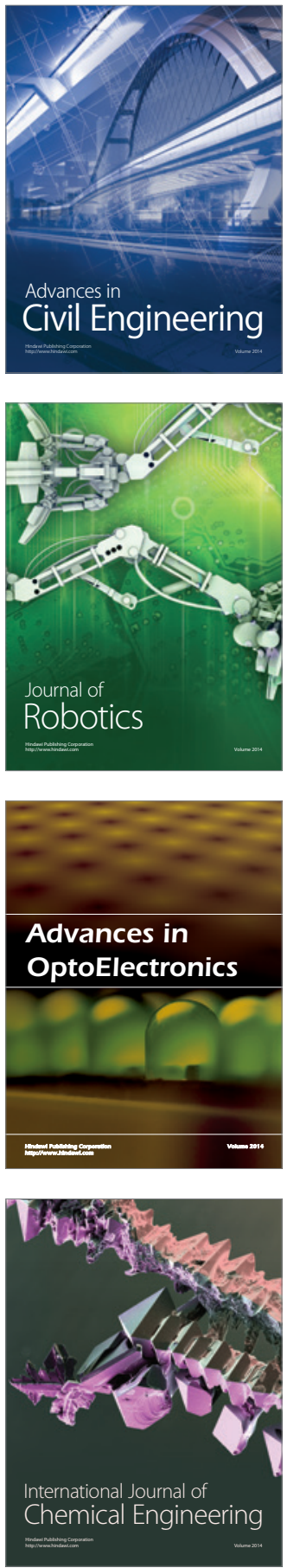

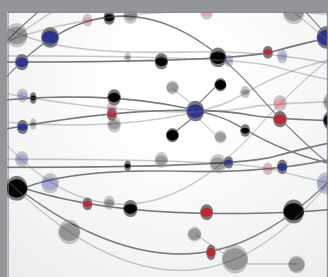

The Scientific World Journal

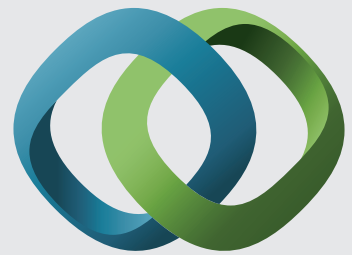

\section{Hindawi}

Submit your manuscripts at

http://www.hindawi.com
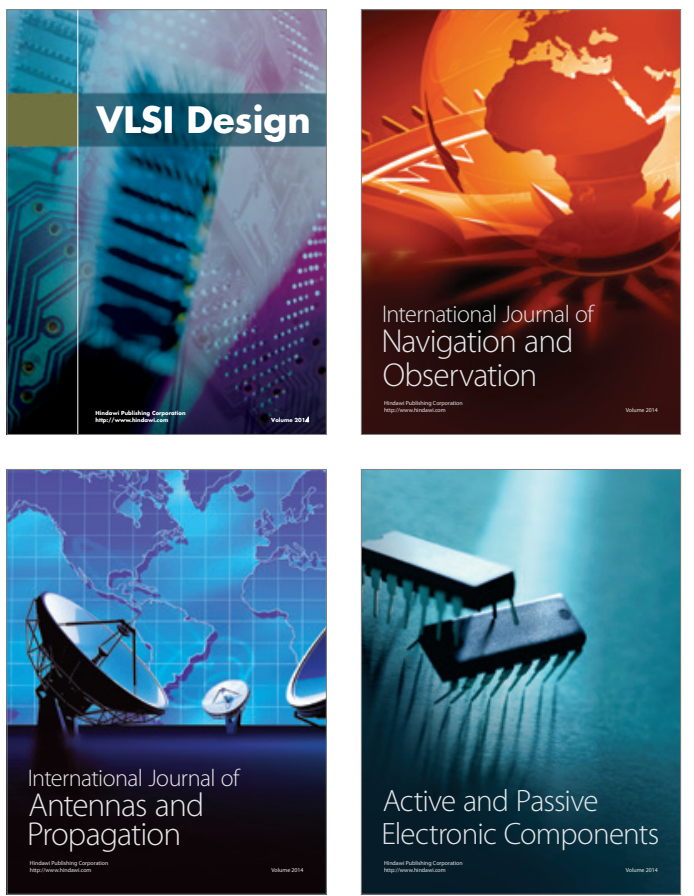
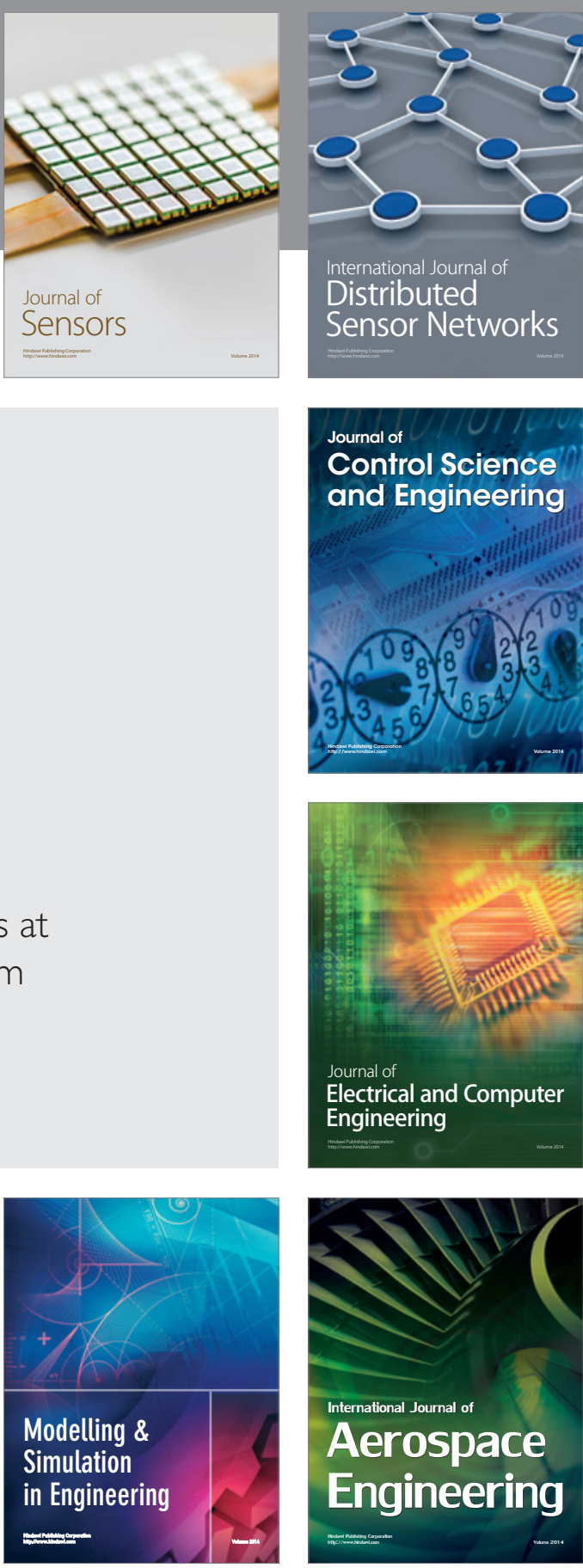

International Journal of

Distributed

Sensor Networks

Journal of

Control Science

and Engineering
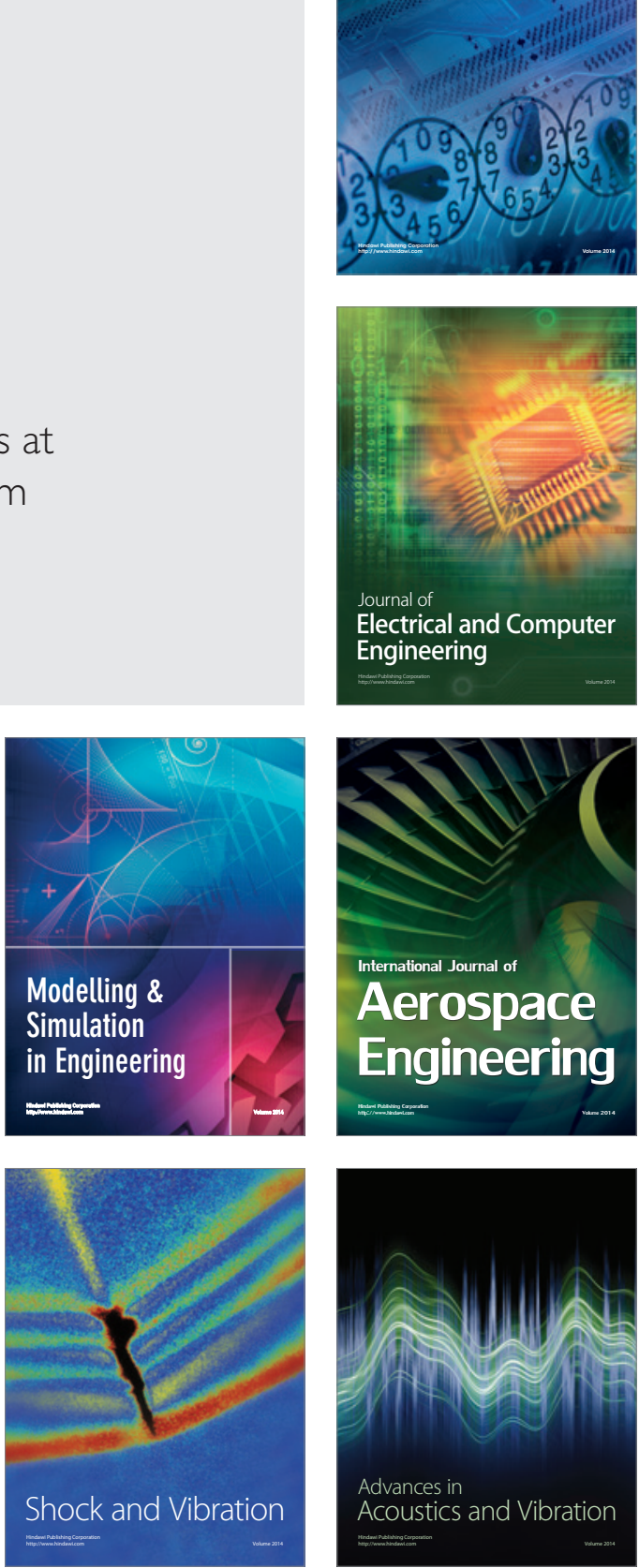